\title{
Publisher Correction: In situ anodic generation of hydrogen peroxide
}

Carlos Ponce de León

Correction to: Nature Catalysis https://doi.org/10.1038/s41929-020-0432-2, published online 19 February 2020.

In the version of this News \& Views originally published, the name of author Carlos Ponce de León was coded wrongly, resulting in it being incorrect when exported to citation databases. This has been corrected, though no visible changes will be apparent.

Published online: 26 February 2020

https://doi.org/10.1038/s41929-020-0444-y

๑) Springer Nature Limited 2020 